\title{
INVESTMENT ACTIVITY AND ENTREPRENEURSHIP IN STARA ZAGORA REGION
}

\author{
D. Stoyancheva*, R. Angelova \\ Industrial Business and Entrepreneurship Department, Trakia University, Stara Zagora, Bulgaria
}

\begin{abstract}
Investments are widely recognized as the engine of economic activity and growth. In the recent years, trends in Bulgaria reveal a significant decline in investment activity, attended by strong reservations of entrepreneurs to invest, as well as withdrawal of the foreign capital from the owners. The aim of the study is to examine and assess the size and dynamics of investments, including foreign direct and domestic investments, and the impact of foreign direct investments on the entrepreneurs' decisions. Along with analyzing national data, comparative analysis is applied for the trends in the Stara Zagora region.
\end{abstract}

Key words: investments, innovations, financing, industry, entrepreneurship

\section{INTRODUCTION}

Investments are recognized a key factor in economic growth. Petrakos and Arvanitidis (1) summarize that investments are a key determinant of economic growth identified in neoclassical as well as endogenous growth model. The theory is supported by numerous scientific studies, including Kormendi and Meguire (2); Levine and Renelt (3); Mankiw (4), Auerbach et al (5); Barro and Sala-iMartin (6), Sala-i-Martin (7); Easterly (8); Podrecca u Carmeci (9). On the one hand, the scientific interest is attracted by the direct effects of increased cash flows to the local economies, respectively the impact on employment, incomes and domestic demand, while other studies focused on the "secondary" effects on the dynamics of domestic investment and the entry into and exit from the market of local businesses.

In Bulgaria the impact of foreign direct investment (FDI) arise the scientific interest in several directions. Popov (10) examines the structure and quality of industry investment with emphasis on their methodological and practical application in terms of their characteristics. Radulova (11) analyzes the dynamics and volume of FDI and concludes they accounted for a significant share in the

\footnotetext{
*Correspondence to: Dimitrina Stoyancheva, Industrial Business and Entrepreneurship Department, Trakia University,Stara Zagora,
}

Bulgaria, stoyancheva@uni-sz.bg, Phone:+35942699419

formation of GDP. Studying the post-crisis economy of Bulgaria, Angelov (12) indicates that the quality of investments is poor and their contribution to economic development is questionable.

The period 2008-2013 in Bulgaria coincides with the spreading of global financial and economic crisis. Bulgaria did not stand aside from the financial storm and transferred negative effect mostly through the withdrawal of foreign capital back to the owners' countries. Primarily because of a great number of domestic factors, the effects of global financial crisis accelerated the manifestation of economic crisis in Bulgaria. During that period, the ruling elite failed to offer relevant and applicable management decisions. Negative effects of non-resident capital withdrawal was felt noticeably after 2009 and mainly found expression in the strong contraction of investment activity, including FDI and domestic investment, and a delay of investment project implementation.

In a prolonged recession, combined with frequently changing and non-transparent macroeconomic decisions, the behavior of foreign investors is not a surprise. They continue to re-direct their capital out of Bulgaria, and as a result the negligible growth of FDI has become a sustainable trend. Downward trend was observed in the dynamics 
of domestic investments too. During the same period, household savings in the banking system increase significantly, but have not contributed to the intensification of loan market and investment growth.

In this paper, we attempt to examine and assess the investment activity during the $2008-2013$ period using comparative analysis of statistical information, at regional and national level, and a survey of entrepreneurs'opinion. The authors proves the thesis that the impact of economic crisis on entrepreneurship occurs in the following aspects:

1) Changes in the structure of enterprises by size - a reduction of the number of small, medium and large enterprises and an increase in the share of micro-enterprises;
2) Reduction in the demand for external financing;

3) Determining low confidence in the credit markets and decisions of the ruling elite.

Above-mentioned direct effects could be pointed key determinants for the reduction of investment activity in Stara Zagora region.

\section{CHANGING STRUCTURE OF BUSINESS}

National Statistical Institute (NSI) data on dynamics in the number of enterprises in Bulgaria for the period $2008-2013$ trends to a slight increase. There is a similar tendency in Stara Zagora region. Total number of enterprises in 2008 is 14000 . Within the same period a slight reduction is noticed (for example, there is a decline in 2010 compared to 2009), but as a whole at the end of 2013 the number of enterprises is 14427 - See Table 1.

Table 1. Number of enterprises

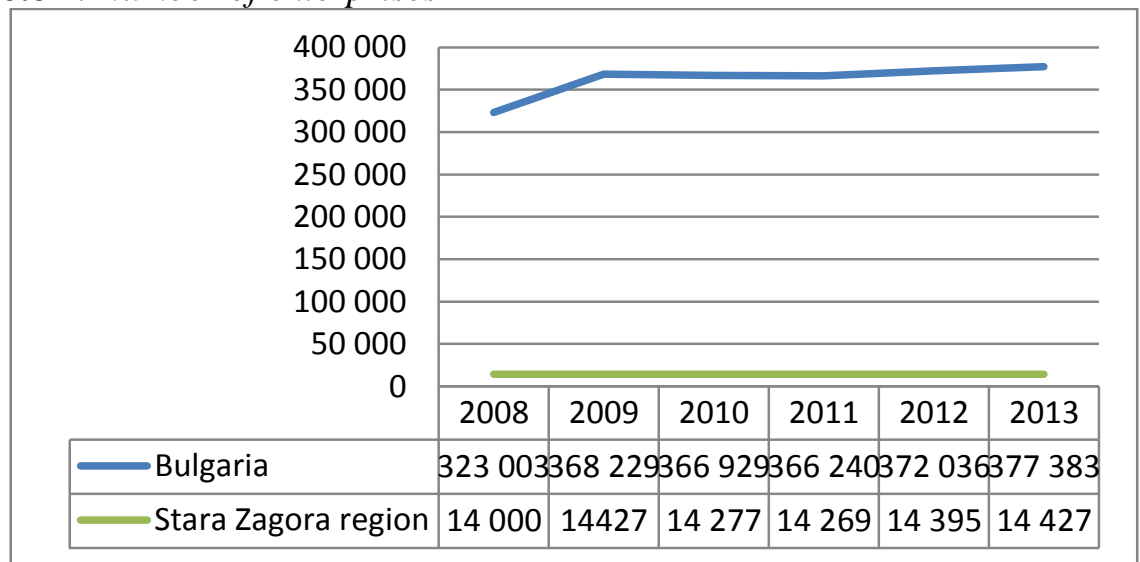

Source: NSI data

More interesting is the information about the structure of enterprises by size according to number of employees - See Table 2 and Table 3. As at the national level and at the district level there is a change in 2013 compared to 2008. The share of large, medium and small enterprises decrease and increase that of microenterprises.

Table 2. Structure of Bulgarian enterprises by size according to number of employees - 2008 to 2013.

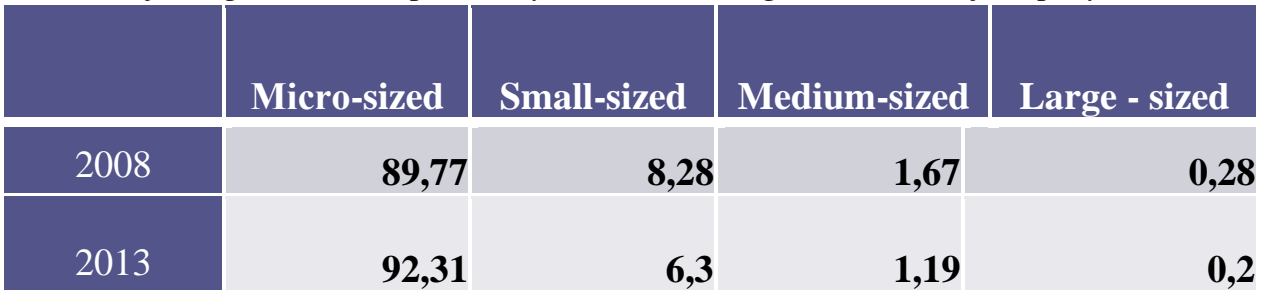

Source: NSI data

Table 3. Structure of Stara Zagora region enterprises by size according to number of employees - 2008 to 2013.

\begin{tabular}{|r|r|r|r|r|} 
& Micro-sized & Small-sized & Medium-sized & Large - sized \\
\hline 2008 & $\mathbf{9 0}$ & $\mathbf{8 , 1}$ & $\mathbf{1 , 6}$ & $\mathbf{0 , 3}$ \\
\hline 2013 & $\mathbf{9 1 , 9}$ & $\mathbf{6 , 7}$ & $\mathbf{1 , 2}$ & $\mathbf{0 , 2}$ \\
\hline
\end{tabular}

Source: NSI data 
Micro-sized enterprises are characterized by a greater dynamism in the percentage of newly opened or closed. Basically they are uncompetitive and more difficult to cope with the financial crisis - characterized by lower productivity, lower profitability and low labor costs, market-oriented mainly to the domestic market, etc. . This makes them less attractive for lending and investing in them. Their investment activity is less pronounced, especially in the innovative aspect.

\section{INVESTMENT ACTIVITY}

Investment activity in the country draws up a downward trend, investment spending shows weak dynamics

resulting in declining growth rate of investments - See Figure 1 .

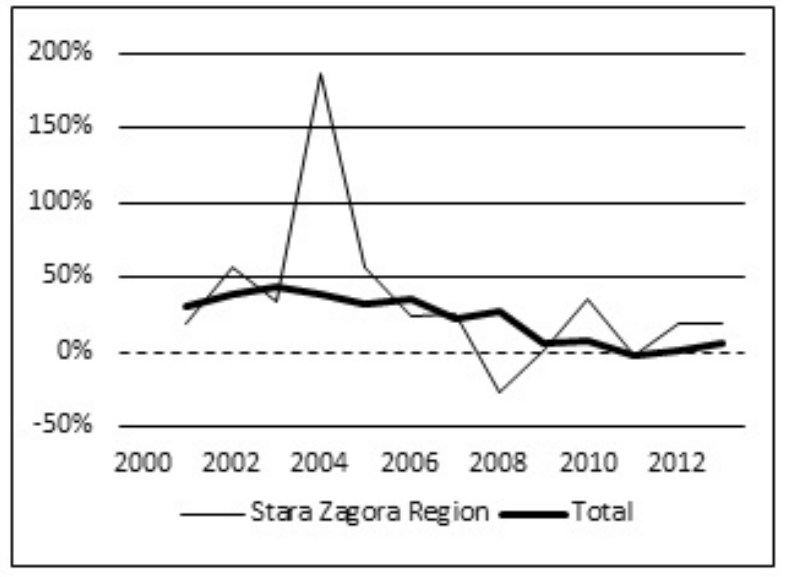

Figure 1. FDI Growth Rate (2000-2013)

Against the decline in total FDI, investments in the region are characterized by more expressed dynamics compared to FDI for the country. Figure 1 highlights the following features of investment activity in Stara Zagora region:

- For most of the period considered investment activity, investments in Stara Zagora region exceeds the total of the country;

- The trend of outflow of foreign capital since 2008 is significantly less pronounced in Stara Zagora region;

- FDI in this region retain higher increasing rate;

- Level of investments manifests Stara Zagora region as a destination with a favorable investment environment.

In the analysis of investment activity in the region of Stara Zagora it is necessary to indicate the dominant role of enterprises in the energy sector. Enterprises for the production of electricity have a determining contribution to the high levels of investment (13). Significant potential for investments growth could be found in the opportunities for improving the regional business environment. Entrepreneurs involved in the survey expressed an unambiguously negative assessment of the work and commitment of local authorities and administrative services to the business problems (14);

Domestic investment dynamics of enterprises in Stara Zagora region, measured as expenditures on acquisition of tangible fixed assets, shows different values. By 2012, investment activity in the region significantly lags behind the total for the country - See Figure 2.

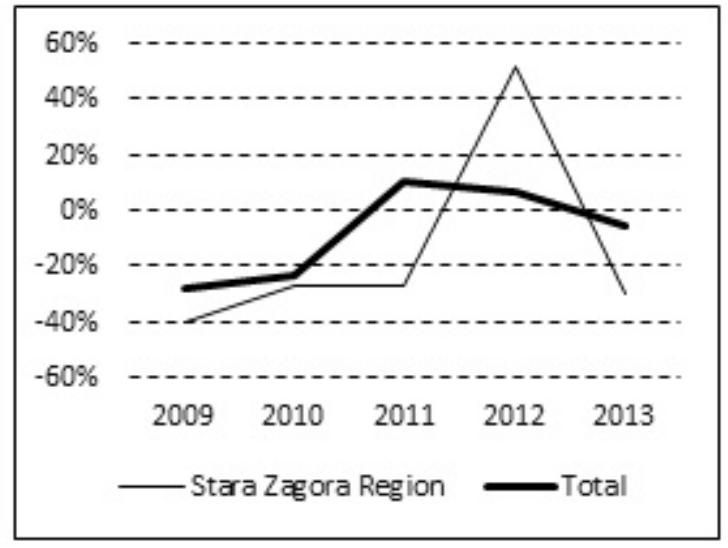

Figure 2. Domestic Investments Growth Rate (2008-2013) 
It is evident that the negative effects of contraction in the economic activity have not been overcome yet and exhibit long-term impact on corporate activity. Only in the last two years one could see a faster growing rate of investment, but as a whole it still remains weak and not sufficient to stimulate economic growth in the region.

\section{INVESTMENTS AND FINANCING OF BUSINESS - SURVEY DATA}

A survey on 54 entrepreneurs from Stara Zagora region has been made in order to analyze the evolution of the above mentioned trends and processes. The research does not claim to be representative, but the collected data help to reveal and explain the behavior of entrepreneurs related to their future investment decisions. In particular, an attempt is made to follow the propensity of entrepreneurs to demand external financing and as well as their intentions for financing future business investments.

The main results of the empirical study are summarized below.

The results of the survey reveal that investments are directed mainly towards purchasing fixed assets for the provision of productive activity. Expenditures in machinery and equipments takes the highest share of $65 \%$ of total invested funds - See Figure 3.

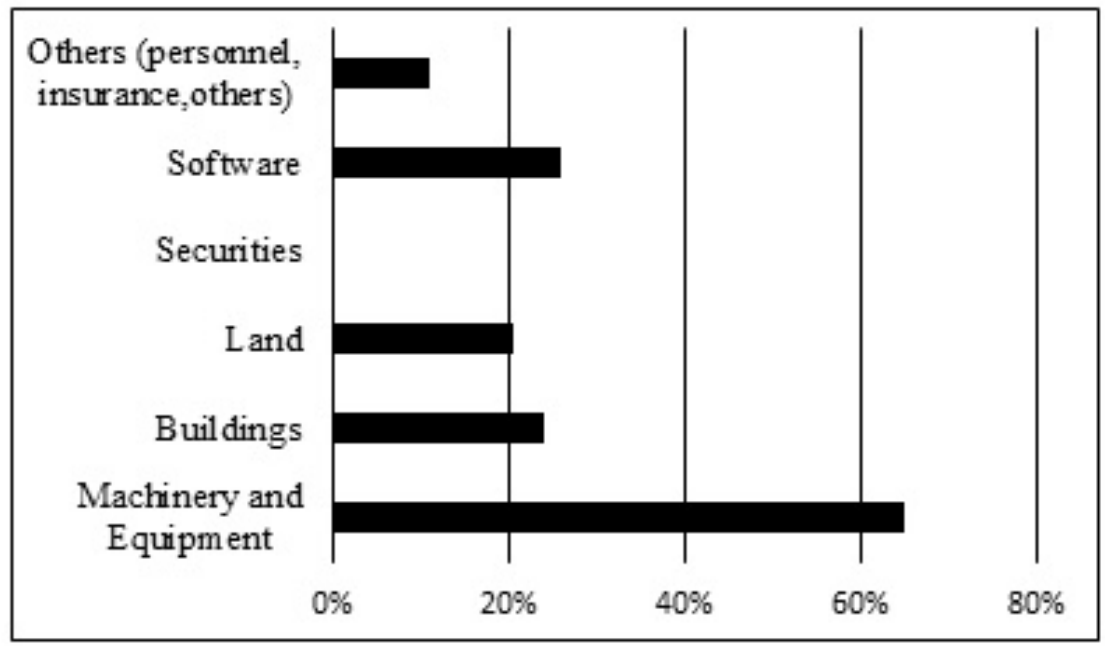

Figure 3. Investments for the last 5 years

At the same time, investments in human resources lag behind and those in financial assets (securities) are near nil. Less than half of enterprises have invested funds to purchase their own buildings and/or land.
Asked how to prefer to finance their investments, entrepreneurs shows explicit preference to the use of traditional sources of financing - See Figure 4. Over $40 \%$ of them indicated that they used bank loans to finance the investments in the last 5 years.

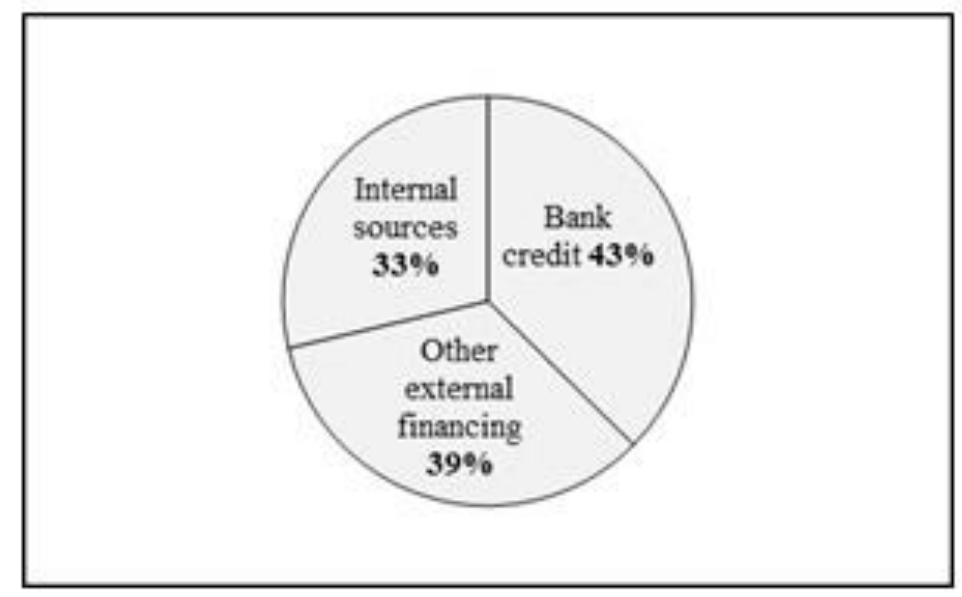

Figure 4. Sources of funding in the last 5 years

Indicative is the fact that nearly $50 \%$ of the investment projects financed with bank loans are co-financed under programs from state or
EU structural funds. Should be mentioned, as well, that the share of enterprises which prefer 
to finance their investments solely by internal sources is high (about 33\%). Companies who

indicated that they are not willing to use bank credit also started their business exclusively with own funds /savings/. Nevertheless, the need of external financing is obvious as enterprises refuse to apply for bank loans, but at the same time we observe demand for funding under the EU programs. As a whole it is observed a weak demand for external sources of financing and clearly expressed lack of trust in the banking institutions. Related to the funding under government and EU funding programs - the assessment of the business is not straightforward. Over $44 \%$ of the enterprises indicated that they do not apply for such funding as the procedures for application are too complicated $(75 \%$ of them indicated this response), and the level of related information and awareness is low.

The amount of loans demanded also suggests that enterprises tend to invest mainly in costreduction projects, and much less focus is put on market-expansion and innovations projects. Enterprises demand bank loans primarily to the amount of BGN 500000 that corresponds with the highest share of investments in machinery and equipment - See Figure 5.

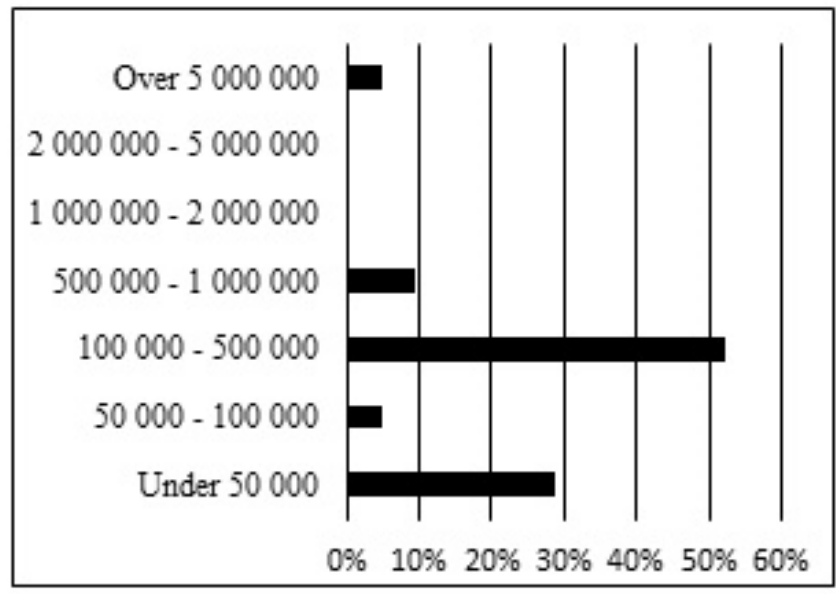

Figure 5. Loan Size, BGN

Enterprises consider business development mostly as an increase in the rate of sales. More than $60 \%$ of them pointed out that they plan to "increase the volume of sales"- See Figure 6.

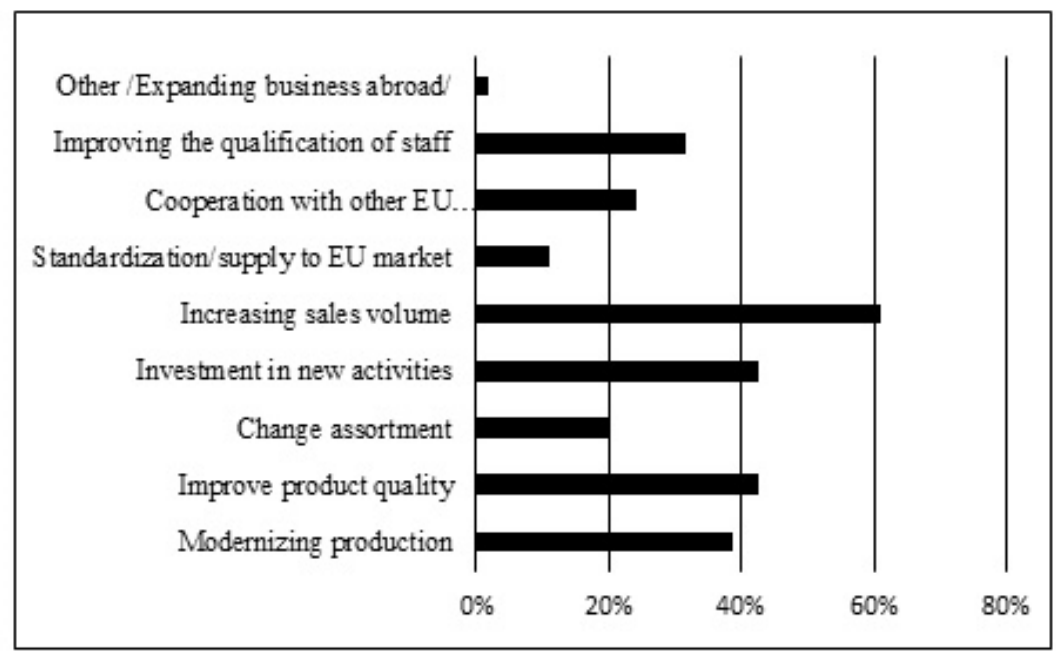

Figure 6. Intentions for business development

Yet non-performing innovation projects deepen the problem with anyway low levels of innovations in Bulgaria. In terms of absorption of new technologies Bulgaria is in unfavorable position in the ranking of the World Economic Forum - we rank $125^{\text {th }}$ of 144 countries. The share of enterprises engaged in high-tech production in Bulgaria is $1 \%$ - twice lower than in the EU. The ector "Research and
Development" in Bulgaria is three times smaller (15). And in short-term there have not objective circumstances to change that perspective.

Entrepreneurs' future intentions related to the amount of bank loans for business development, like the demand for loans in the past five years, do not exceed BGN 500000 See Figure 7. 


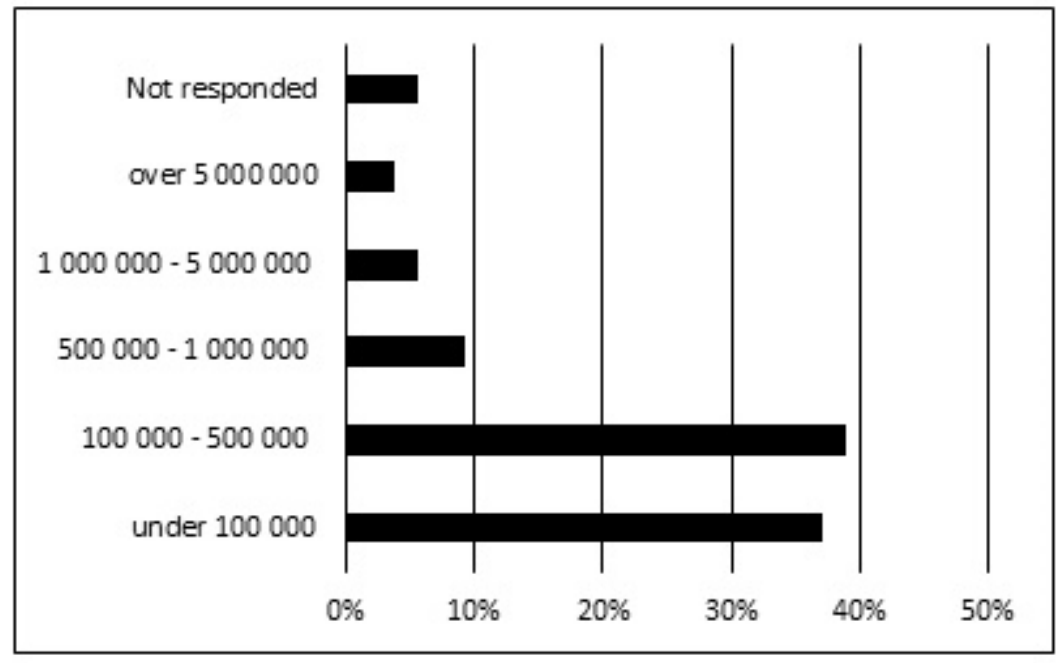

Figure 7. Necessary funds over the next 3 years, BGN

It is clear that entrepreneurs from Stara Zagora region tend to delay significant investment and especially innovation projects and the negative effects of the economic crisis (shrinking the size of enterprises and volume of production, reducing the demand for external financing and etc.) are yet to be overcome.

\section{CONCLUSION}

Reduction of investment flows since 2008 till now is an expression of high sensitivness of the investors, including foreign and domestic investors, to the negative changes in economic conditions in Bulgaria. Withdrawing foreign capital clearly shows the investors' uncertainty as to the ability of ruling elite to apply countercyclical measures to improve the economic conditions. Initial contraction in the investment demand has not been addressed with timely and relevant measures by the macroeconomic management. Subsequent weak investment dynamics (downward trend) shows that there has not been taken an effective economic policy to increase the net inflow of FDI and the volume of domestic investments.

The results of the survey in Stara Zagora region support the general conclusions. Enterprises' investment activity in the region remain weak, investment expenditures are mainly aimed at ensuring the productive activity. Yet the efforts are directed primarily at cost-reduction investment projects, and less expenditures are involved in innovative projects. Increasing innovation activity of enterprises is significant and unresolved question whose severity is underlined by strong lagging technological development of Bulgarian enterprises compared to the global trends.
Investments in human resources, product quality and enterprise growth are not satisfactory. Enterprises' investment activity remain constrained by the low demand for external financing and limited access to credit markets. In the presence of significant intercompany indebtedness the share of enterprises that have minimized their demand for external financing is noteworthy. The need for policy actions to improve access to external financing is evident and can be achieved in two directions - by applying measures for restoring confidence in the credit markets and providing better information awareness of application procedures for program funding. At microeconomic level, the effectiveness of corporate governance needs to be improved.

\section{REFERENCES}

1. Petrakos, G., P. Arvanitidis, Determinants of economic growth. Economic Alternatives, 1, 2008.

2. Kormendi, R. and P. Meguire, Macroeconomic determinants of growth: cross-country evidence. Journal of Monetary Economics, 16(4):141-163, 1985.

3. Levine, R. and D. Renelt, A sensitivity analysisof cross-country growth regressions. American Economic Review, 82(4):942-963, 1992.

4. Mankiw, N., D. Romer and D. Weil, A contribution to the empirics of economic growth. Quarterly Journal of Economics, 107:407-437, 1992.

5. Auerbach, A., K. Hassett and S. Oliner Reassessing the social returns to equipment investment. Quarterly Journal of Economics, 109:789-802, 1994. 
6. Barro R. and X. Sala-i-Martin, 11. Economic growth. New York, McGrawHill, 1995.

7. Sala-i-Martin, X., I just ran two million regressions. American Economic Review, Papers and Proceedings, 87 (2):178-183, 1997.

8. Easterly, W. and S. Rebelo, Fiscal policy and economic growth: an empirical invesigation. Journal of Monetary Economics, 32(3):417-458, 1993.

9. Podrecca, E. and G. Carmeci, Fixed investment and economic growth: new results on causality. Applied Economics, 33:177-182, 2001.

10.Popov, G., Trends in foreign investment in the industry of Bulgaria. Economic Alternatives, 4:53-60, 2008.

11.Radulova, A., The Impact of Foreign Direct Investment on the Economic Development of Bulgaria. Economic Thought, 5:54, 2011.
12. Angelov, I., The post crisis economy of Bulgaria. Economic Thought, 2:24-50, 2010.

13.Minasian, G., The economy of Stara Zagora region: Status, Factors , Constrains. Scientific Conference "145 years Bulgarian Academy of Sciences", Regional Academic Centre, Stara Zagora, Conference Proceedings, 2014.

14.Atanasova, T., D., Stoyancheva, Assessment of business opinion in Stara Zagora - potential, constraints and opportunities for development. Scientific Conference "145 years Bulgarian Academy of Sciences", Regional Academic Centre, Stara Zagora, Conference Proceedings, 2014.

15.ASME, Research on entrepreneurship and prospects for innovation in SMEs 20122013, p. 10, 2013. 